TITLE:

\title{
Iron-catalyzed AlkylAlkyl negishi coupling of organoaluminum reagents
}

\section{$\operatorname{AUTHOR}(\mathrm{S}):$}

Agata, Ryosuke; Kawamura, Shintaro; Isozaki, Katsuhiro; Nakamura, Masaharu

\section{CITATION:}

Agata, Ryosuke ...[et al]. Iron-catalyzed AlkylAlkyl negishi coupling of organoaluminum reagents. Chemistry Letters 2019, 48(3): 238-241

\section{ISSUE DATE:}

2019-03

URL:

http://hdl.handle.net/2433/245569

\section{RIGHT:}

(C) 2019 The Chemical Society of Japan.; Publisher permitted to deposit the accepted manuscript on this repository:; This is not the published version. Please cite only the published version.; この論文は出版社版でありません。引用の際には出版社版をご確認 ご利用ください。 


\title{
Iron-catalyzed Alkyl-Alkyl Negishi Coupling of Organoaluminum Reagents
}

\author{
Ryosuke Agata, ${ }^{1,2}$ Shintaro Kawamura, ${ }^{\dagger 1,2}$ Katsuhiro Isozaki, ${ }^{1,2}$ and Masaharu Nakamura*1,2 \\ ${ }^{1}$ International Research Center for Elements Science (IRCELS), Institute for Chemical Research (ICR), \\ Kyoto University, Uji, Kyoto 611-0011, Japan \\ ${ }^{2}$ Department of Energy and Hydrocarbon Chemistry, Graduate School of Engineering, \\ Kyoto University, Nishikyo-ku, Kyoto 615-8510, Japan
}

E-mail: masaharu@scl.kyoto-u.ac.jp

The first iron-catalyzed cross-coupling reaction of alkyl halides with alkylaluminum reagents (alkyl-alkyl Negishi coupling) is developed using an iron/bisphosphine catalyst system. The reaction shows high functional group tolerance: various primary alkyl halides possessing a nonprotected indole, carboxyl, or hydroxy group are coupled with primary alkylalumimuns in good yields. Potassium fluoride plays a key role to promote the reaction by generating an aluminate species which facilitates the 0 transmetalation between the organoaluminum and the iron catalyst.

\section{Keywords: Iron, Cross coupling, Organoaluminum}

Cross-coupling reaction forming $\mathrm{C}_{\mathrm{sp} 3}-\mathrm{C}_{\mathrm{sp} 3}$ bonds is one 14 of the key chemical transformations in synthetic organic 15 chemistry. ${ }^{1}$ In the last two decades, transition-metal16 catalyzed alkyl-alkyl cross-coupling reactions have been 17 extensively developed by mainly nickel and palladium 18 catalysts (Figure 1a). ${ }^{2-7}$ The first alkyl-alkyl coupling was 19 reported by Knochel and co-workers using dialkylzinc 20 reagents and alkyl iodides bearing a terminal olefin in the 21 presence of nickel catalyst. ${ }^{3}$ This achievement has led to the 22 development of a variety of alkyl-alkyl cross-coupling 23 reactions with not only alkylzinc, ${ }^{4}$ but also alkyl Grignard, ${ }^{5}$ 24 and alkylboron reagents, ${ }^{6}$ applied in the synthesis of bio-

\section{active natural products and pharmaceuticals. ${ }^{4 \mathrm{~d}, 6 \mathrm{c}}$}

Recently, increasing attention has been focused on iron as a sustainable catalyst in organic synthesis due to its non-toxic, environmentally benign nature, and highabundance in the Earth's crust. ${ }^{8,9}$ Considerable efforts have thus been devoted to developing iron-catalyzed crosscoupling reactions forming $\mathrm{C}_{\mathrm{sp} 2}-\mathrm{C}_{\mathrm{sp} 3}, \mathrm{C}_{\mathrm{sp} 2}-\mathrm{C}_{\mathrm{sp} 2}, \mathrm{C}_{\mathrm{sp}}-\mathrm{C}_{\mathrm{sp} 2}$, and $\mathrm{C}_{\mathrm{sp}}-\mathrm{C}_{\mathrm{sp} 3}$ bonds to date. ${ }^{10-12}$ However, there are only limited reports for $\mathrm{C}_{\mathrm{sp} 3}-\mathrm{C}_{\mathrm{sp} 3}$ bond-forming reactions. Chai, Cárdenas, and Kambe reported iron-catalyzed Kumada-type alkyl-alkyl coupling between alkyl Grignard reagents and alkyl halides (Figure 1b). ${ }^{13}$ Our group previously reported the Suzuki-type alkyl-alkyl coupling by using alkylboronates as nucleophiles. ${ }^{14}$ There is still room for improvement in functional group tolerance and substrate scope on electrophiles and/or nucleophiles, because these reactions require the use of Grignard reagents and highly reactive organolithium to activate the organoboron nucleophiles. In contrast, we previously reported the synthetic utility of organoaluminum reagents in ironcatalyzed Negishi-type coupling reactions, which enable the compatibility with a range of functional groups under mild activation condition. ${ }^{12}$ Therefore, we envisioned the applicability of organoaluminum reagents to iron-catalyzed alkyl-alkyl coupling to overcome the above limitations.

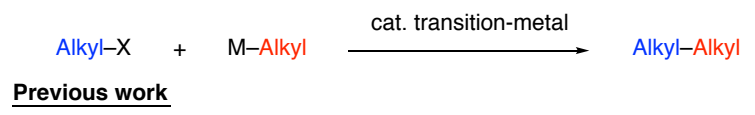

(a) Pd, Ni, Co, or Cu catalyst $(\mathrm{X}=\mathrm{I}, \mathrm{Br}, \mathrm{Cl}, \mathrm{F}$, OTs, etc.; $\mathrm{M}=M g, Z n, B)$

(b) Fe catalyst $(\mathrm{X}=\mathrm{I}, \mathrm{Br}, \mathrm{F}, \mathrm{OTs} ; \mathrm{M}=\mathrm{Mg}, \mathrm{B})$

Kumada-type coupling $(\mathrm{M}=M g)$ : low functional group tolerance

Suzuki-type coupling $(\mathrm{M}=B)$ : require $i-\mathrm{PrMgCl}$ to activate alkylborane

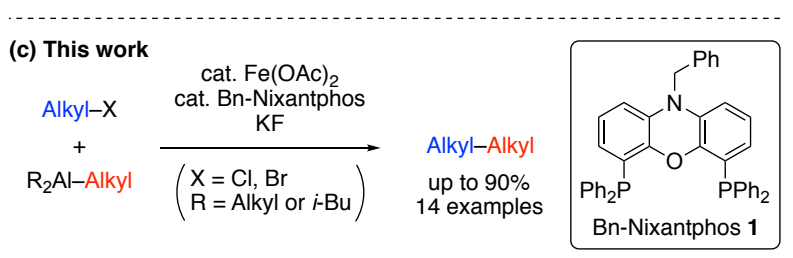

50

51

52 $\checkmark$ high functional group tolerance: $\mathrm{CN}, \mathrm{CO}_{2} \mathrm{R}, \mathrm{CO}_{2} \mathrm{H}, \mathrm{OH}, \mathrm{NHR}$

Scheme 1. Transition-metal-catalyzed cross coupling between alkyl electrophiles and alkylmetal reagents.

Herein, we report a new iron-catalyzed alkyl-alkyl cross-coupling reaction of non-activated alkyl halides with alkylaluminum reagents by using catalytic amounts of $\mathrm{Fe}(\mathrm{OAc})_{2}$ and Bn-Nixantphos $\mathbf{1}^{15}$ (Figure 1c). The addition of potassium fluoride ${ }^{12 c}$ was found to be the key to attain the facile coupling reaction. This reaction system shows high functional group compatibility, which has not been achieved by previous iron catalysts.

We chose the coupling reaction between (6bromohexyl)benzene (2a) and trioctylaluminum as a model reaction. After the screening of catalyst precursors, ligands, additives, and reaction conditions, a wide bite angle bisphosphin 1 was found to give the desired coupling product 3a in $83 \%$ yield (entry 1). Comparable catalytic activities (64 and 72\%) were observed by using its congeners, TBS-Nixantphos and Xantphos (entries 2 and 3). ${ }^{16}$ It should be noted that these reaction conditions suppressed the undesired $\beta$-hydrogen elimination completely and olefin $4 \mathbf{a}$ and 1-octene were not observed at all (see SI, Table S1). On the other hand, a structurally flexible bisphosphine ligand, DPEphos, resulted in low selectivity, likely due to the dissociation of one phosphine from the iron center, which enables competitive side reactions such as the $\beta$-hydrogen elimination (entry 4). A narrow bite angle bisphosphine, SciOPP, did not give the desired product 3a, despite its effectiveness in the ironcatalyzed cross-coupling reaction of alkyl halides (entry 5). ${ }^{10 \mathrm{~b}}$ When $i$-Pr-Pybox ${ }^{4 \mathrm{c}}$ and N-heterocyclic carbene (NHC) precursor IPr $\cdot \mathrm{HCl}^{4 \mathrm{~b}}$ were used, almost no desired product 3a was obtained (entries 6 and 7). Other mono- and bisphosphine, diamine, ${ }^{10 \mathrm{a}}$ and NHC precursors ${ }^{13 \mathrm{~b}}$ were 
1 Table 1. Effect of reaction parameters in iron-catalyzed cross 2 coupling of $2 \mathbf{a}$ with trioctyltaluminum ${ }^{\mathrm{a}}$

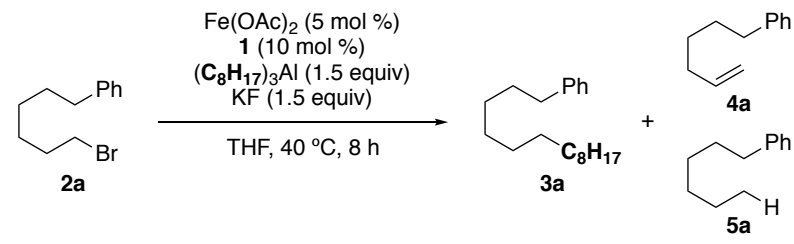

\begin{tabular}{|c|c|c|c|c|c|}
\hline \multirow{2}{*}{ Entry } & \multirow{2}{*}{ Changes from the optimal conditions } & \multicolumn{4}{|c|}{ Yield $(\%)^{\mathrm{b}}$} \\
\hline & & 3a & $4 a$ & $\mathbf{5 a}$ & $\operatorname{RSM}^{\mathrm{c}}$ \\
\hline 1 & none & 83 & 0 & 16 & 0 \\
\hline 2 & TBS-Nixantphos instead of $\mathbf{1}$ & 64 & 0 & 7 & 12 \\
\hline 3 & Xantphos instead of $\mathbf{1}$ & 72 & 0 & 15 & 0 \\
\hline 4 & DPEPhos instead of $\mathbf{1}$ & 20 & 23 & 37 & 0 \\
\hline 5 & SciOPP instead of $\mathbf{1}$ & 0 & 29 & 50 & 0 \\
\hline 6 & $i$-Pr-Pybox instead of $\mathbf{1}$ & 0 & 1 & 9 & 84 \\
\hline 7 & $\mathrm{IPr} \cdot \mathrm{HCl}$ instead of $\mathbf{1}$ & 4 & 21 & 35 & 7 \\
\hline 8 & $\mathrm{FeCl}_{2}$ instead of $\mathrm{Fe}(\mathrm{OAc})_{2}$ & 17 & 17 & 33 & 26 \\
\hline 9 & $\mathrm{Fe}(\mathrm{OPiv})_{2}$ instead of $\mathrm{Fe}(\mathrm{OAc})_{2}$ & 70 & 0 & 16 & 0 \\
\hline 10 & $\mathrm{Fe}(\mathrm{OTf})_{2}$ instead of $\mathrm{Fe}(\mathrm{OAc})_{2}$ & 70 & 0 & 16 & 4 \\
\hline $11^{\mathrm{d}}$ & $\mathrm{FeCl}_{2}$ and $\mathrm{KOAc}(30 \mathrm{~mol} \%)$ instead of $\mathrm{Fe}(\mathrm{OAc})_{2}$ & 76 & 0 & 8 & 0 \\
\hline 12 & without 1 & $<1$ & 23 & 36 & 37 \\
\hline 13 & without $\mathrm{Fe}(\mathrm{OAc})_{2}$ & 0 & 0 & 5 & 92 \\
\hline 14 & without KF & $<1$ & 0 & 5 & 95 \\
\hline
\end{tabular}

4 a Reactions were carried out on $0.2-0.8 \mathrm{mmol}$ scale. ${ }^{\mathrm{b}}$ Determined by 5 quantitative $\mathrm{GC}$ analysis using undecane as an internal standard.

$6{ }^{\mathrm{c}}$ Recovery of starting material $\mathbf{2 a}$. ${ }^{\mathrm{d}} \mathrm{FeCl}_{2}(5 \mathrm{~mol} \%)$ was treated with

$7 \mathrm{KOAc}(30 \mathrm{~mol} \%)$ in $\mathrm{MeOH} / \mathrm{THF}$ for $1 \mathrm{~h}$ and then the solvent was

8 removed in vacuo.

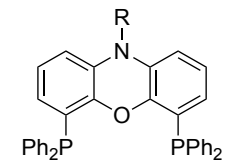

$\mathrm{R}=\mathrm{Bn}: \mathrm{Bn}-\mathrm{Nixantphos} 1$ $R=$ TBS: TBS-Nixantphos
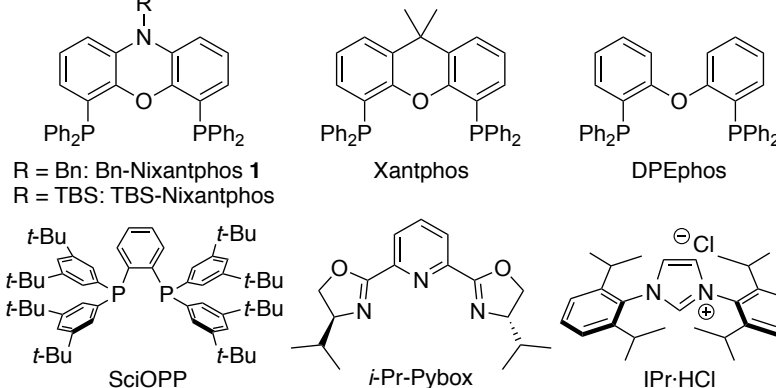

Xantphos

DPEphos ineffective in this reaction, where significant amounts of byproducts, $\mathbf{4 a}, \mathbf{5 a}$, and 1-octene were formed (see SI, Table S1). The present coupling reaction thus requires the use of wide bite angle bisphosphine ligands possessing rigid framework to achieve high selectivity of the coupling product.

The counter anion of the iron salts showed remarkable influence on the product yield and selectivity. As shown in entry $8, \mathrm{FeCl}_{2}$ showed lower reactivity and selectivity than $\mathrm{Fe}(\mathrm{OAc})_{2}$. On the other hand, the iron salts having oxoanions, $\mathrm{Fe}(\mathrm{OPiv})_{2}$ and $\mathrm{Fe}(\mathrm{OTf})_{2}{ }^{10 \mathrm{e}}$ resulted in much higher yields than the chloride, albeit displaying lower selectivity than $\mathrm{Fe}(\mathrm{OAc})_{2}$ (entries 9 and 10 , see also SI, Table S2). As shown in entry 11, pretreatment of $\mathrm{FeCl}_{2}$ with potassium acetate dramatically improved the yield and selectivity compared with $\mathrm{FeCl}_{2}$ alone. In the absence of bisphosphine ligand $\mathbf{1}, \mathrm{Fe}(\mathrm{OAc})_{2}$, or $\mathrm{KF}$, almost no desired
28 product was obtained (entries 12-14). Notably, the addition 29 of fluoride anion is critical for attaining the rapid conversion 30 of the alkyl bromide, which can be accounted for facilitating 31 the transmetalation step by the formation of a highly 32 reactive aluminate species. ${ }^{12 c, 17}$ These results indicate that 33 the $\mathrm{Fe}(\mathrm{OAc})_{2} / \mathbf{1}$ catalyst with $\mathrm{KF}$ is crucial to achieve high 34 catalytic activity and suppress undesired side reactions.

Table 2 illustrates the scope and limitations of the present reaction under optimal conditions. A variety of

37 Table 2. Substrate scope of alkyl halides and alkylaluminum 38 reagents $^{\mathrm{a}}$

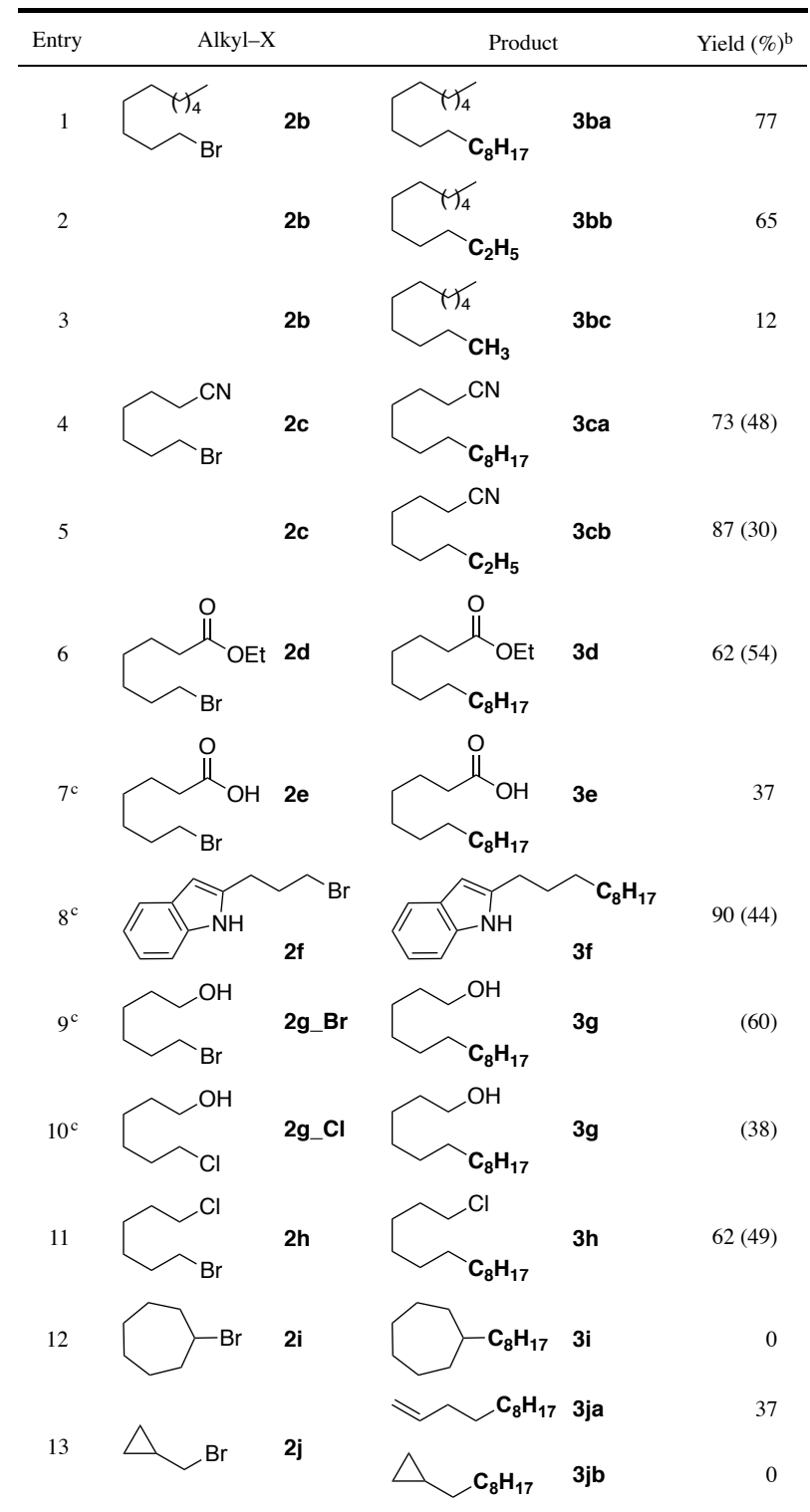

a Reactions were carried out on a $1 \mathrm{mmol}$ scale using $\mathrm{Fe}(\mathrm{OAc})_{2}(5$ $\mathrm{mol} \%), \mathbf{1}(10 \mathrm{~mol} \%)$, and alkylaluminum reagents (1.5 equiv) in THF at $40{ }^{\circ} \mathrm{C}$ for $8-44 \mathrm{~h}$, see the SI for details of the reaction conditions for each entry. ${ }^{b}$ Determined by quantitative GC analysis using undecane as $45{ }^{\mathrm{c}}$ Trioctylaluminum (2.5 equiv) was used. 
1 alkylaluminum reagents were cross-coupled with 1-

2 bromodecane (2b). The reactions of trioctylaluminum or

3 triethylaluminum with $\mathbf{2 b}$ gave the corresponding coupling 4 products $\mathbf{3 b a}$ and $\mathbf{3 b b}$ in $77 \%$ and $65 \%$ yields, respectively 5 (entries 1 and 2). In contrast, trimethylalminum afforded 6 only $12 \%$ yield of product $3 \mathbf{b c}$, where decene was obtained 7 as the major by-product (entry 3$).{ }^{18}$

We then studied the scope of alkyl halides and to our delight the present reaction showed high functional group tolerance. Alkyl bromides bearing a reactive functional group, such as cyano or ester group, reacted with alkylaluminum reagents to give the corresponding coupling products 3ca-d in good yields (62-87\%, entries 4-6). Importantly, alkyl halides possessing a non-protected indole, carboxyl, and hydroxy group ${ }^{19}$ also participated in the reactions to afford the corresponding products $\mathbf{3 e - g}$ in $37-$ $90 \%$ yield, despite the catalyst poisoning effect of these functional groups in iron-catalyzed coupling reactions of alkyl halides (entries 7-9). ${ }^{10 \mathrm{~b}}$ An even more challenging primary alkyl chloride bearing a hydroxy group 2g_Cl can also be cross-coupled with trioctylaluminum reagent to give the product $\mathbf{3 g}$ in $38 \%$ yield (entry 10 ). We consider that organoaluminum reagent deprotonate the acid proton and the resulting aluminum salts of the substrate undergo facile cross-coupling reaction. ${ }^{12 \mathrm{~b}, 20}$ The reaction of 1-bromo-6chlorohexane (2h) showed high chemoselectivity and proceeded exclusively at the bromide site to afford $\mathbf{3 h}$ in $62 \%$ yield (entry 11). The reaction of secondary alkyl bromide, bromocycloheptane (2i) with trioctylaluminum reagent did not produce the desired coupling product, whereas undesired by-products, cycloheptane, cycloheptene, and 1,1'-bi(cycloheptane) were obtained in 14\%, 46\%, and $12 \%$ yields, respectively (entry 12). The reaction of (bromomethyl)cyclopropane $(\mathbf{2} \mathbf{j})^{21}$ gave the corresponding ring-opening/coupling product $\mathbf{3}$ ja in $37 \%$ yield without the formation of $\mathbf{3 j b}$ indicating the intermediacy of alkyl radicals (entry 13$).{ }^{11,13 \mathrm{~b}}$

We further conducted a sequential hydroalumination $22 /$ cross-coupling reaction. Addition of DIBAL-H to olefin 6 and the subsequent iron-catalyzed cross-coupling reaction with $\mathbf{2} \mathbf{b}$ proceeded in a one-pot manner to give the desired coupling product $3 \mathbf{k a}$ in $36 \%$ yield along with the formation of minor by-product $\mathbf{3 k b}$ (Scheme 2). Although there is still room for improving the
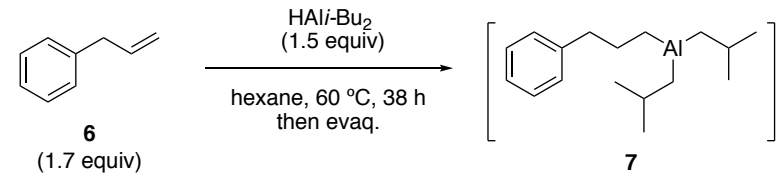

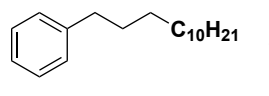

3ka, 36\% (GC yield)

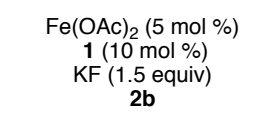

THF, $40^{\circ} \mathrm{C}, 40 \mathrm{~h}$
72 product yield and selectivity, this consecutive transformation displays the synthetic potential of the present coupling reaction. ${ }^{23}$

Based on the above-described results and previous mechanistic studies on iron-catalyzed cross-coupling reactions, ${ }^{11 \mathrm{~d}-\mathrm{f}}$ a plausible reaction mechanism featuring an $\mathrm{Fe}^{\mathrm{I}} / \mathrm{Fe}^{\mathrm{II}} / \mathrm{Fe}^{\mathrm{III}}$ manifold is presented in Figure 1 . The catalytic cycle starts from the bisphosphine-iron(I) intermediate A which forms by the reduction of $\mathrm{Fe}(\mathrm{OAc})_{2}$ in the presence of ligand $\mathbf{1}{ }^{11 \mathrm{~b}, 24}$ The reaction of $\mathbf{A}$ with the alkyl halide $\mathbf{2}$ forms the alkyl radical intermediate and the iron(II) intermediate B. Transmetalation of $\mathbf{B}$ with the organoaluminate species generates the organoiron(II) intermediate $\mathbf{C}$, which can undergo rapid recombination with the alkyl radical to produce the organoiron(III) intermediate $\mathbf{D}^{11 \mathrm{~d}-\mathrm{f}}$ The catalytic cycle then completes by reductive elimination to give the $\mathrm{C}_{\mathrm{sp} 3}-\mathrm{C}_{\mathrm{sp} 3}$ coupling product $\mathbf{3}$, regenerating the iron(I) intermediate $\mathbf{A}$. We consider that the wide bite angle ligand promotes the reductive elimination and the acetate ligand occupying the vacant coordination sites $^{25}$ suppresses the undesired $\beta$-hydrogen elimination.

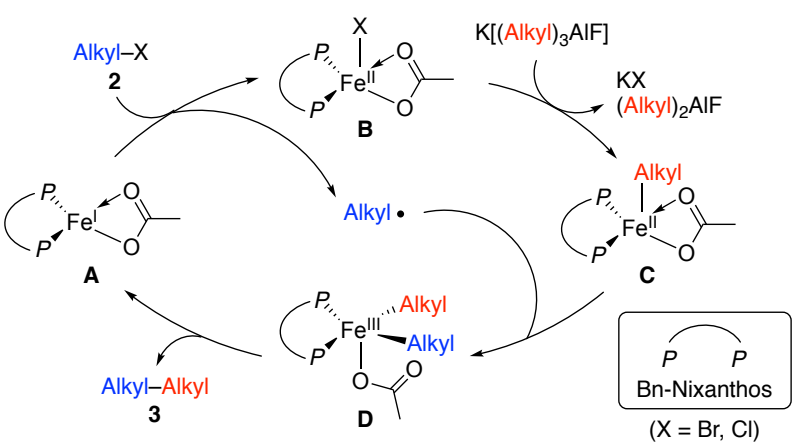

Figure 1. A possible reaction mechanism.

In conclusion, the first example of iron-catalyzed alkyl-alkyl Negishi coupling of organoaluminum has been achieved employing an $\mathrm{Fe}(\mathrm{OAc})_{2} / \mathbf{1}$ catalyst system. Stoichiometric potassium fluoride was identified as the critical additive that facilitates the coupling reactions by the formation of highly nucleophilic aluminate species. This new coupling method features the simple and mild activation of organoaluminum nucleophiles, resulting in high functional group tolerance, and thus demonstrates synthetic advantages especially in high product selectivity over previously reported iron-catalyzed alkyl-alkyl coupling reactions.

This work was supported in part by the Advanced Low Carbon Technology Research and Development Program (ALCA JPMJAL1504) from the Japan Science and Technology Agency (JST), and JSPS Core-to-Core Program "Elements Function for Transformative Catalysis and Materials". R.A. thanks 'Research Fellowships of Japan Society for the Promotion of Science for Young Scientists' (JSPS 11488). We are grateful to Integrated Research hydroalmination with diisobutylaluminum hydride. 
1 Consortium on Chemical Sciences (IRCCS). FT-ICR-MS

2 and $800 \mathrm{MHz}$ NMR analyses were supported by the JURC

3 at ICR, Kyoto University. The authors thank Profs. Hideo

4 Nagashima and Yusuke Sunada for providing $\mathrm{Fe}(\mathrm{OPiv})_{2}$.

5 We are grateful to Tosoh Finechem Corporation and Nissan

6 Chemical Industries Corporation for their financial support.

7

8 Supporting Information is available electronically on $\mathrm{J}$ -

9 STAGE.

\section{References and Notes}

11

12 2-1 Hirosawa, Wako, Saitama, 351-0198, Japan.

1 For selected review: R. Jana, T. P. Pathak, M. Sigman, Chem. Rev. 2011, 111, 1417-1492.

2 For selected reviews: a) M. R. Netherton, G. C. Fu, $A d v$. Synth. Catal. 2004, 346, 1525-1532. b) J. Terao, N. Kambe, Acc. Chem. Res. 2008, 41, 1545-1554. c) N. Kambe, T. Iwasaki, J. Terao, Chem. Soc. Rev. 2011, 40, 4937-4943. d) X. Hu, Chem. Sci. 2011, 2, 1867-1886.

3 A. Devasagayaraj, T. Stüdemann, P. Knochel, Angew. Chem. Int. Ed. 1995, 34, 2723-2725.

4 For selected papers, see: a) J. Terao, H. Todo, H. Watanabe, A. Ikumi, N. Kambe, Angew. Chem. Int. Ed. 2004, 43, 6180-6182. b) N. Hadei, E. A. B. kantchev, C. J. O'Brien, M. G. Organ, Org. Lett. 2005, 7, 3805-3807. c) V. B. Phapale, E. Buñuel, M. García-Iglesias, D. J. Cárdenas, Angew. Chem. Int. Ed. 2007, 46, 8790-8795. d) S. Son, G. C. Fu, J. Am. Chem. Soc. 2008, 130, 2756-2757.

5 For selected papers, see: a) J. Terao, H. Watanabe, A. Ikumi, H. Kuniyasu, N. Kambe, J. Am. Chem. Soc. 2002, 124, 4222-4223. b) G. Cahiez, C. Chaboche, C. Duplais, A. Guilliani, A. Moyeux, Adv. Synth. Catal. 2008, 350, 1484-1488. c) O. Vechorkin, X. Hu, Angew. Chem. Int. Ed. 2009, 48, 2937-2940.

6 For selected papers, see: a) T. Brenstrum, D. A. Gerristma, G. M. Adjabeng, C. S. Frampton, J. Britten, A. J. Robertson, J. McNulty, A. Capretta, J. Org. Chem. 2004, 69, 7635-7639. b) B. Saito, G. C. Fu, J. Am. Chem. Soc. 2007, 129, 9602-9603. c) X. Jiang, S. Sakthivel, K. Kulbitski, G. Nisnevich, M. Gandelman, $J$. Am. Chem. Soc. 2014, 136, 9548-9551.

7 For selected papers on oxidative Tsuji-Trost allylic alkylation, see: a) S. Lin, C.-X. Song, G.-X. Cai, W.-H. Wang, Z.-J. Shi, J. Am. Chem. Soc. 2008, 130, 12901-12903. b) S. Tang, X. Wu, W. Liao, K. Liu, C. Liu, S. Luo, A. Lei, Org. Lett. 2014, 16, 35843587.

8 a) C. Bolm, J. Legros, J. Le Paih, L. Zani, Chem. Rev. 2004, 104, 6217-6254. b) W. M. Czaplik, M. Mayer. J. Cvengroš, A. J. von Wangelin, ChemSusChem 2009, 2, 396-417. c) E. Nakamura, T. Hatakeyama, S. Ito, K. Ishizuka, L. Ilies, M. Nakamura, Organic Reactions, 2014, 83, pp. 1-210. d) I. Bauer, H.-J. Knölker, Chem. Rev. 2015, 115, 3170-3387. e) J. E. Zweig, D. E. Kim, T. R. Newhouse, Chem. Rev. 2017, 117, 11680-11752. f) H. Nagashima, Bull. Chem. Soc. Jpn. 2017, 90, 761-775.

E. Nakamura, K. Sato, Nature Mater. 2011, 10, 158-161.

10 For selected papers on the $\mathrm{C}_{\mathrm{sp} 2}-\mathrm{C}_{\mathrm{sp} 3}$ bond formation, see: a) $\mathrm{M}$. Nakamura, K. Matsuo, S. Ito, E. Nakamura, J. Am. Chem. Soc. 2004, 126, 3686-3687. b) T. Hatakeyama, T. Hashimoto, Y. Kondo, Y. Fujiwara, H. Seike, H. Takaya, T. Tamada, M. Ono, M. Nakamura, J. Am. Chem. Soc. 2010, 132, 10674-10676. c) A. Fürstner, R. Martin, H. Krause, G. Seidel, R. Goddard, C. W. Lehmann, J. Am. Chem. Soc. 2008, 130, 8773. For selected papers on the $\mathrm{C}_{\mathrm{sp} 2}-\mathrm{C}_{\mathrm{sp} 2}$ bond formation, see: d) T. Hatakeyama, $\mathrm{S}$. Hashimoto, K. Ishizuka, M. Nakamura, J. Am. Chem. Soc. 2009, 131, 11949. e) Y.-Y. Chua, H. A. Duong, Chem. Commun. 2016, $52,1466-1469$. For selected paper on the $\mathrm{C}_{\mathrm{sp}}-\mathrm{C}_{\mathrm{sp} 2}$ and $\mathrm{C}_{\mathrm{sp}}-\mathrm{C}_{\mathrm{sp} 3}$ bond formations, see: f) T. Hatakeyama, Y. Okada, Y. Yoshimoto, M. Nakamura, Angew. Chem. Int. Ed. 2011, 50, 10973-10976.
68

69

11 For a recent mechanistic study on iron-catalyzed cross-couplings of alkyl halides, see: a) D. Noda, Y. Sunada, T. Hatakeyama, M. Nakamura, H. Nagashima, J. Am. Chem. Soc. 2009, 131, 60786079. b) R. B. Bedford, P. B. Brenner, E. Carter, J. Clifton, P. M. Cogswell, N. J. Gower, M. F. Haddow, J. N. Harvey, J. A. Kehl, D. M. Murphy, E. C. Neeve, M. L. Neidig, J. Nunn, B. E. R. Snyder, J. Taylor, Organometallics 2014, 33, 5767-5780. c) H. Takaya, S. Nakajima, N. Nakagawa, K. Isozaki, T. Iwamoto, R. Imayoshi, N. J. Gower, L. Adak, T. Hatakeyama, T. Honma, M. Takagaki, Y. Sunada, H. Nagashima, D. Hashizume, O. Takahashi, M. Nakamura, Bull. Chem. Soc. Jpn. 2015, 88, 410418. d) M. Jin, L. Adak, M. Nakamura, J. Am. Chem. Soc. 2015, 137, 7128-7134. e) A. K. Sharma, W. M. C. Sameera, M. Jin, L. Adak, C. Okuzono, T. Iwamoto, M. Kato, M. Nakamura, K. Morokuma, J. Am. Chem. Soc. 2017, 139, 16117-16125. f) W. Lee, J. Zhou, O. Gutierrez, J. Am. Chem. Soc. 2017, 139, 1612616125. g) V. E. Fleischauer, S. B. Muñoz, P. G. N. Neate, W. W. Brennessel, M. Neidig, Chemi. Sci. 2018, 9, 1878-1891.

12 For the iron-catalyzed Negishi-type couplings using organoaluminum reagents, see: a) S. Kawamura, K. Ishizuka, H. Takaya, M. Nakaura, Chem. Commun. 2010, 46, 6054-6056. b) S. Kawamura, T. Kawabata, K. Ishizuka, M. Nakamura, Chem. Commun. 2012, 48, 9376-9378. c) S. Kawamura, R. Agata, M. Nakamura, Org. Chem. Front. 2015, 2, 1053-1058.

13 a) K. G. Dongol, H. Koh, M. Sau, C. L. L. Chai, Adv. Synth. Catal. 2007, 349, 1015-1018. b) M. Guisán-Ceinos, F. Tato, E. Buñuel, P. Calle, D. J. Cárdenas, Chem. Sci. 2013, 4, 1098-1104. c) T. Iwasaki, R. Shimizu, R. Imanishi, H. Kuniyasu, N. Kambe, Chem. Lett. 2018, 47, 763.

14 T. Hatakeyama, T. Hashimoto, K. K. A. D. S. Kathriarachchi, T. Zenmyo, H. Seike, M. Nakamura, Angew. Chem. Int. Ed. 2012, $51,8834-8837$.

15 L. A. van der Veen, P. H. Keeven, G. C. Schoemarker, J. N. H. Reek, P. C. J. Kamer, P. W. N. M. van Leeuwen, M. Lutz, A. L. Spek, Organometallics 2000, 19, 872-883.

16 For the X-ray crystal structure of $\mathrm{FeCl}_{2}$ (Xantphos), see: J. L. Kneebone, V. E. Fleischauer, S. L. Daifuku, A. A. Shaps, J. M. Bailey, T. E. Iannuzzi, M. L. Neidig, Inorg. Chem. 2016, 55, 272-282.

17 J. J. Harrison, D. L. Beach, D. C. Y. Young, K. S. Seshadri, J. D. Nelligan, Organometallics 1987, 6, 343-346.

18 Decene, decane, and starting material were observed in $58 \%$, $0.7 \%$, and $24 \%$ yields, respectively. Unfavorable low-valent or peralkylated iron species would be easily generated by the less bulky trimethylaluminum, leading to undesired side reactions.

19 The aluminum alkoxide species is known to enhance the crosscoupling reaction of 1-chlorohexanol (ref. 12b), however the reaction between 1-chlorohexanol and trioctylaluminum did not proceed without $\mathrm{KF}$.

20 The reaction of 1-chlorohexanol with octylmagnesium chloride did not provide the desired coupling product.

21 V. W. Bowry, J. Lusztyk, K. U. Ingold, J. Am. Chem. Soc. 1991, $113,5687-5698$.

22 K. Ziegler, H. Martin, F. Krupp, Liebigs Ann. Chem. 1960, 629, 14-19.

23 Other by-products decene, decane, icosane, and starting material were observed in $18 \%, 8 \%, 13 \%$, and $13 \%$ yields, respectively. We assume that the $\beta$-hydrogen elimination from isobutyliron intermediates affords iron hydride intermediates which cause the undesired side reactions.

24 The reduction of iron(II) acetate by organoaluminum reagent in THF may give dimeric iron(I) acetate species, which can generate the monomeric iron(I) acetate $\mathbf{A}$ in an equilibrium manner. For the crystal structure of origomeric iron(II) acetate, see: B. Weber, R. Betz, W. Bauer, S. Schlamp, Z. Anorg. Allg. Chem. 2011, 102-107.

25 a) M. Wakioka, Y. Nakamura, Q. Wang, F. Ozawa, Organometallics 2012, 31, 4810-4816. b) Y. Tan, J. F. Hartwig, J. Am. Chem. Soc. 2011, 133, 3308-3311. 
NOTE The diagram is acceptable in a colored form. Publication of the colored G.A. is free of charge. For publication, electronic data of the colored G.A. should be submitted. Preferred data format is EPS, PS, CDX, PPT, and TIFF. If the data of your G.A. is "bit-mapped image" data (not "vector data"), note that its print-resolution should be 300 dpi.

You are requested to put a brief abstract (50-60words, one paragraph style) with the graphical abstract you provided, so that readers can easily understand what the graphic shows.

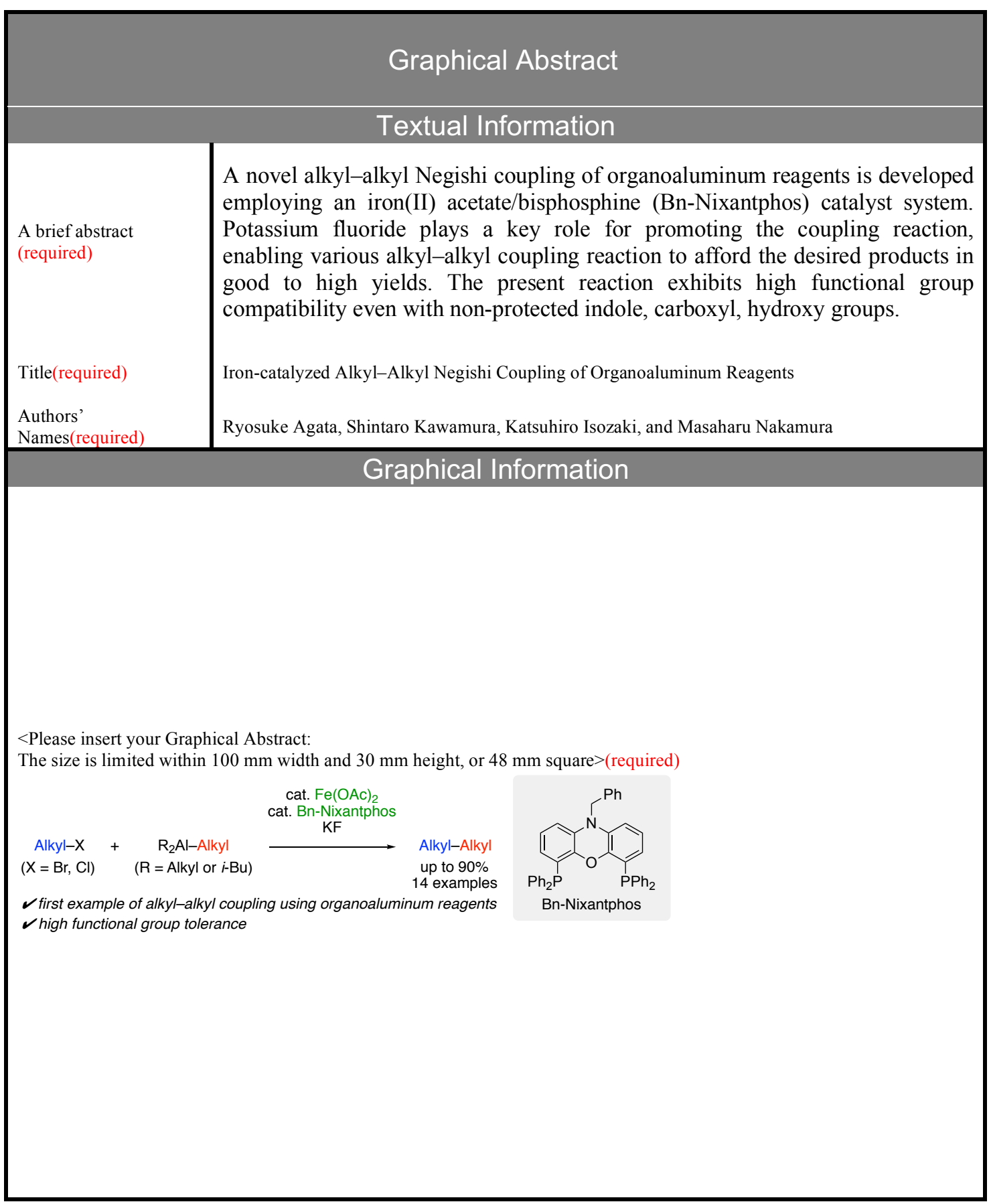

